\title{
OPEN The severity of adverse drug reactions and their influencing factors based on the ADR monitoring center of Henan Province
}

\author{
Ziqi Yan ${ }^{1}$, Zhanchun Feng ${ }^{1}$, Zhiming Jiao ${ }^{1}$, Chaoyi Chen ${ }^{1}$, Ganyi Wang ${ }^{2}$ \& Da Feng ${ }^{3 凶}$
}

Adverse drug reactions (ADRs) may be a serious public health problem and have received widespread attention in recent years. This study has analyzed the factors leading to the occurrence of serious ADRs (SADRs), determined the factors affecting the prognosis of patients with severe adverse reactions at different levels of medical institutions, and finally made corresponding recommendations for the monitoring, prevention, and treatment of SADRs. We used descriptive analysis and chi-square test to analyze the year, age, gender, proportion of SADRs, and the results of the ADRs in the report. Use the logistic regression to analyze the factors affecting the prognosis of SADRs in different levels of medical institutions. A total of 387642 people's 394037 ADRs were collected from the Henan Provincial Adverse Drug Reaction Monitoring Center from 2016 to 2020. Among them 35742 cases of serious ADRs (9.1\%), 96.1\% were eventually relieved or cured, but 39 cases of SADRs caused death. The main causes of death included hemorrhages, organ failure, and allergies. Age, number of medication and illnesses, level of medical institution, history of adverse reactions, and type and method of medication were all factors that affected the severity of ADR. The prognosis of SADRs is worse than normal ADRs. The ADRs in autumn and winter and new adverse reactions are unique risk factors found in this study. The elderly and patients with multiple diseases or taking multiple drugs should pay attention to their adverse reactions. They should be closely observed within a week after taking the medicine. The supervision of patients with a history of allergies and new adverse reactions should be strengthened by primary medical institutions, and in nonprimary medical institutions should paid attention with past medical histories, and use imported drugs and biological agents with caution to ensure the safety and health of patients.

Given the increased development and utilization of drugs, adverse drug reactions (ADRs) have gradually become a public concern ${ }^{1,2}$. ADRs refer to unrelated or unexpected adverse reactions of qualified drugs under normal usage and dosage ${ }^{3}$. Serious ADR (SADR), a heterogeneous reaction completely unrelated to normal pharmacological effects, cannot be detected by conventional toxicological screening, has a low incidence, and is delayed, not dependent on dose, and unpredictable ${ }^{4}$. Once SADRs occur, multiple organs throughout the body are involved, seriously threatening the life and safety of patients.

SADRs seriously threaten the lives and health of patients and cause a lot of waste of medical resources. From 1966 to 1996, in the United States, an average of 6.7 in every 100 hospitalized patients have SADRs, and the mortality rate reaches $0.32 \%$. The average length of stay of each hospitalized patient due to ADRs is extended by two days, and the average cost increases by $\$ 2500^{7,8}$. In recent years, the number of ADR reports in China has increased rapidly. The China Adverse Drug Reaction Monitoring System has received 1.676 million ADR reports in 2020 ( 1251 cases per million population), and SADRs account for $10 \%$ of these reports ${ }^{9}$. SADRs increase the cost of medical treatment for patients, may delay the treatment time of patients, and seriously affect the quality

\footnotetext{
${ }^{1}$ School of Medicine and Health Management, Tongji Medical College, Huazhong University of Science and Technology, Wuhan 430030, Hubei, China. ${ }^{2}$ Medical Products Administration and Center for ADR Monitoring of Henan, Zhengzhou 450008, Henan, China. ${ }^{3}$ School of Pharmacy, Tongji Medical College, Huazhong University of Science and Technology, Wuhan 430030, Hubei, China. ${ }^{\circledR}$ email: fengda@hust.edu.cn
} 
of life of patients. SADRs also cause patients to lose trust in doctors, causing both parties to fall into medical disputes and aggravating the tense doctor-patient relationship. SADR has become one of the main factors that increase the uncertainty of clinical drug research and development and may terminate research and development due to damage to the health of patients ${ }^{10}$. Thus, SADRs affect the health of patients and adversely affect the operation of medical institutions.

China has introduced the Adverse Drug Reaction Reporting and Monitoring Provision in $2010^{11}$. By 2015, more than 280000 are registered users of the China Adverse Drug Reaction Monitoring System (an online spontaneous reporting system). Users include pharmaceutical manufacturers, drugstores, and medical institutions, and nearly 16.87 million ADR/event reports are collected from 1999 to $2020^{9}$. The ADR reporting and monitoring have developed rapidly, and report numbers and reporting rates are increasing ${ }^{12}$, providing data support for this research.

Therefore, this study has analyzed the factors leading to the occurrence of SADRs, determined the factors affecting the prognosis of patients with severe adverse reactions at different levels of medical institutions, and finally made corresponding recommendations for the monitoring, prevention, and treatment of SADRs.

\section{Methods}

Data source and preprocessing. The data of the adverse drug reaction reports collected by Adverse Drug Reaction Monitoring Center of Henan Province from January 2016 to December 2020 were classified and analysed, and spontaneously reported by medical institutions, enterprises, and the public in Henan.

Data were cleaned and preprocessed to ensure that they were clean and complete. A total of 571326 initial data were obtained. Everyone will record a code once an ADR occurs, but there are cases where the same code includes multiple entries of different drugs. We use excel to ensure that each code retains one to eliminate duplicate data, and 394037 records of ADRs were retained.

Data analysis. The year, age, gender, proportion of serious adverse reactions, and the results of the adverse reactions in the report were subjected to descriptive analysis and chi-square test. The logistic regression was used to analyze the factors affecting the prognosis of SADRs in different levels of medical institutions. All data analyses were performed using the SPSS 24.0 software (IBM Corp. Armonk, NY). A p-value less than 0.05 was considered statistically significant.

Variable assignment. The variables analyzed all came from the Adverse Drug Reaction Event Report Form. This research encoded and assigned variables in accordance with the Adverse Drug Reaction Reporting and Monitoring Management Measures ${ }^{13}$.

This study based on the regulations of the National Adverse Drug Reaction Monitoring Center, Among the reported ADRs, Death; teratogenic, carcinogenic, or birth defect; permanent sequelae; permanent damage to organ function; leading to hospitalization or prolonged hospital stay were regarded as "Serious ADRs" (Abbreviated as SADR), other cases were regarded as "Normal ADRs".

About the distinction of medical institutions, This study refers to The measures for the administration of the hospital grade issued by the Ministry of Health institutions that mainly provide basic public health services and basic medical services as primary hospitals, and other comprehensive medical institutions as non-primary hospitals in accordance with relevant national policies. All primary institutions are first-level hospitals, secondary hospital is a regional hospital that provides comprehensive medical and health services to multiple communities and undertakes certain teaching and scientific research tasks, tertiary hospitals are usually provincial and municipal hospitals.

Outcome definition. The study outcomes were ADR results and the impact on the original disease. In the binary logistic regression, we defined patients who had recovered from ADRs and had no significant impact on the pre-existing disease as a good prognosis, and defined patients who did not improve or had a worsening of the original disease as a poor prognosis.

Ethics. The study protocol was reviewed. Ethical approval was obtained from the Ethics Committee of Tongji Medical College, Huazhong University of Science and Technology (2020S204).

This study obtained written informed consent statements from all human participants, and obtained the written informed consent statements of Ganyi Wang, the legally authorized representative of the minor participants.

The study protocol is performed in accordance with the relevant guidelines.

\section{Results}

Demographic characteristics of ADRs. Among the 394037 reports of ADRs, Figs. 1 and 2 shows $52.3 \%$ of the patients are women (206 042), and the rest are men (187 473). The difference between genders is not significant. About $93.6 \%$ of patients are of Han nationality, and $36.3 \%$ of patients are older than 60 years old. $1.46 \%$ people (5673) had 2 or more ADRs.

Occurrence of ADRs. According to the occurrence of ADRs in the medication process, $60.5 \%(238545)$ of ADRs occur on the day of medication. About $94.7 \%$ of ADRs occur within one week of medication, and only $0.9 \%$ of adverse reactions occur after one month. 


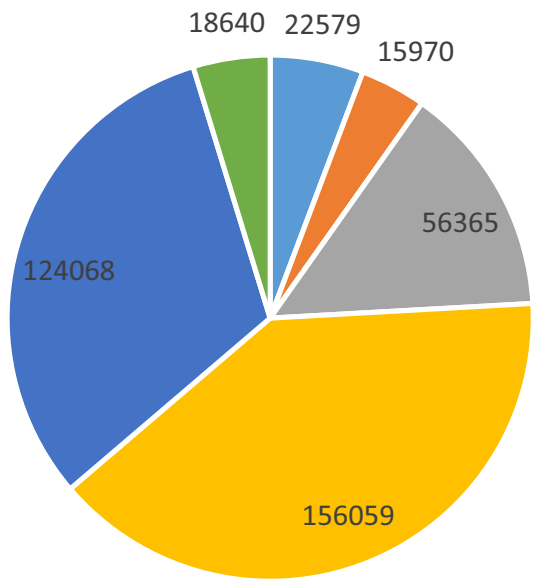

$=0-6 \quad$ - $6-18=18-35 \quad=35-60 \quad-60-80 \quad=>80$

Figure 1. Number of ADR age from 2016 to 2020.

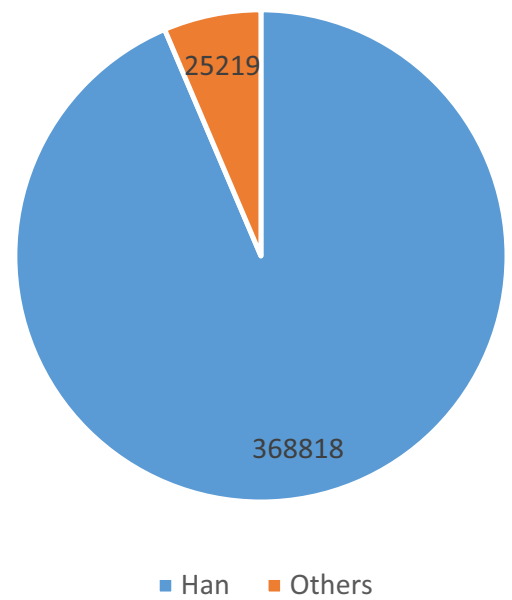

Figure 2. Number of ADR nations from 2016 to 2020.

Reports about ADRs. Figure 3 shows 394037 ADRs in 2016-2020. Both the number of reported ADRs and the proportion of severe ADRs have increased since 2016.

Figure 4 shows the number of ADRs and the proportion of SADRs in different levels of medical institutions. A high hospital level results in high proportion of SADRs.

Severity of ADR in patients with different characteristics. Table 1 summarizes the SADRs in patients with different characteristics. Severity is not related to gender but related to other factors. Underaged and elderly patients, third-level hospitals, patients with new and recurring ADRs, ADRs in autumn and winter, and patients who take drug injections or used imported and biologic durgs have a high proportion of SADRs.

Effect of ADRs. Table 2 shows the results of ADR about different severities and the effects on the original disease. For normal ADRs, $98 \%$ of the cases eventually got better or cured and there was no death.However, for SADRs, only $76.2 \%$ of the cases got better. The proportions of unimproved, worsening, and sequelae are all higher than the group of normal ADRs, and all 39 deaths were also from SADRs group.

Factors affecting the SADRs in different levels of medical institutions. Table 3 shows the factors that affect the SADRs in primary and nonprimary medical institutions. The elderly, who suffer from multiple diseases, have multiple drug behaviors, have a clear history of ADRs, and use injections and patients with ADRs with duration of more than three days and new ADRs patients are likely to have SADRs in all medical institutions. In addition, patients who use proprietary Chinese medicines in primary and nonprimary medical institu- 


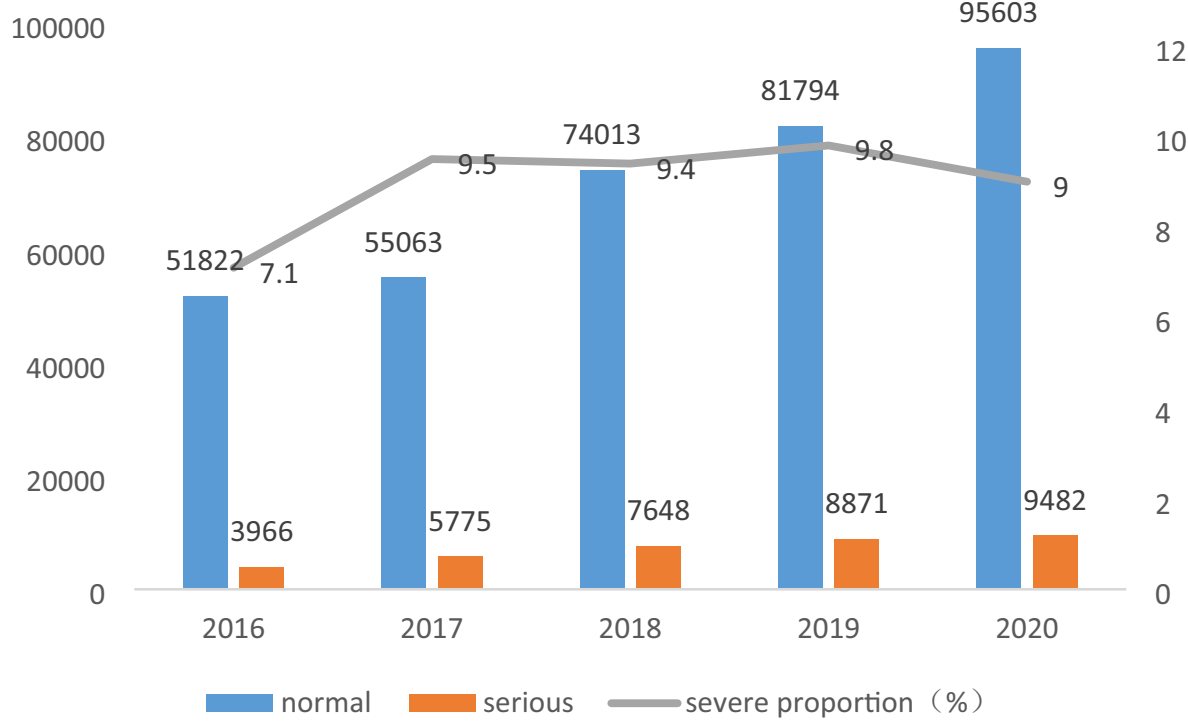

Figure 3. Number of ADR cases from 2016 to 2020.

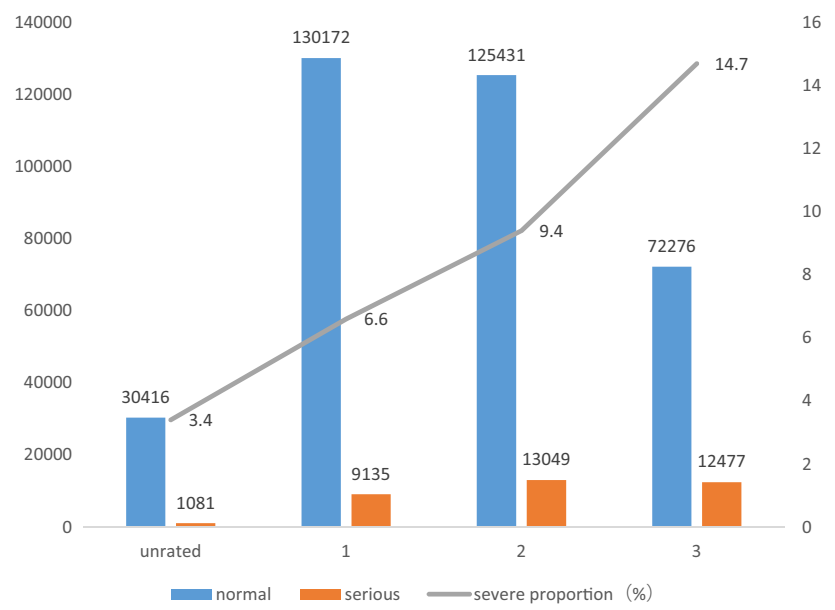

Figure 4. The proportion of SADRs in different levels of medical institutions.

tions have high and low SADR risks, respectively. Similarly, patients with a history of illness and surgery have less risk of seeing a doctor in primary medical institutions than that in nonprimary medical institutions.

ADRs in different levels of medical institutions lead to results. Table 4 reports the prognostic results of ADRs among all patients in different levels. Suffered from multiple diseases, have multiple medications, smoking or drinking, injection, occured in autumn and winter, with a clear history of ADRs and long time interval between medication and ADRs cases have poor prognosis in all medical institutions. The risk of poor prognosis for patients using imported drugs or biologic in primary medical institutions is lower than that of patients using general compound drugs, but the risk of poor prognosis for new ADRs is higher than that of the normal groups, and this conclusion in nonprimary medical institutions is opposite. In addition, the prognosis of ADRs in nonprimary medical institutions in other ways of medication is poor.

\section{Discussion}

This study is a retrospective analysis of a regional section within the database of the spontaneous reporting system of Henan Province. The number of ADRs reported in Henan Province has nearly doubled from 2016 to 2020, and the proportion of SADRs has gradually increased, reaching about $10 \%$. In the future, increased adverse events may occur, and drug safety is facing remarkable challenges ${ }^{14,15}$. 


\begin{tabular}{|c|c|c|c|c|c|}
\hline Variables & Total N (\%) & Nonserious N (\%) & Serious N (\%) & $P$ value & Effect size $(\varphi)$ \\
\hline Total & $394,037(100)$ & $358,295(90.90)$ & $35,742(9.10)$ & & \\
\hline \multicolumn{6}{|l|}{ Age (years) } \\
\hline $0-6$ & $22,579(5.73)$ & $20,888(92.51)$ & $1691(7.49)$ & \multirow{7}{*}{$<0.001$} & \multirow{7}{*}{0.560} \\
\hline $6-18$ & $15,970(4.05)$ & $14,718(92.16)$ & $1252(7.84)$ & & \\
\hline $18-35$ & $56,365(14.30)$ & $52,659(93.42)$ & $3706(6.58)$ & & \\
\hline $35-60$ & $156,059(39.61)$ & $142,930(91.59)$ & $13,129(8.41)$ & & \\
\hline $60-80$ & $124,068(31.48)$ & $110,619(89.16)$ & $13,449(10.84)$ & & \\
\hline$>80$ & $18,640(4.73)$ & $16,468(88.35)$ & $2172(11.65)$ & & \\
\hline Missing & $356(0.10)$ & & & & \\
\hline \multicolumn{6}{|l|}{ Gender } \\
\hline Male & $187,473(47.58)$ & $170,404(90.90)$ & $17,069(9.10)$ & \multirow{3}{*}{0.496} & \multirow{3}{*}{-0.001} \\
\hline Female & $206,042(52.29)$ & $187,411(90.96)$ & $18,631(9.04)$ & & \\
\hline Missing & $522(0.13)$ & & & & \\
\hline \multicolumn{6}{|l|}{ Hospital level } \\
\hline Unrated & 31,497 (7.99) & $30,416(96.57)$ & $1081(3.43)$ & \multirow{4}{*}{$<0.001$} & \multirow{4}{*}{0.119} \\
\hline 1 & $139,307(35.35)$ & $130,172(93.44)$ & $9135(6.56)$ & & \\
\hline 2 & $138,480(35.14)$ & $125,431(90.58)$ & $13,049(9.42)$ & & \\
\hline 3 & $84,753(21.50)$ & $72,276(85.28)$ & $12,477(14.72)$ & & \\
\hline \multicolumn{6}{|l|}{ Medication method } \\
\hline Oral & $165,060(41.89)$ & $159,655(96.72)$ & $5405(3.27)$ & \multirow{3}{*}{$<0.001$} & \multirow{3}{*}{0.180} \\
\hline Injection & $218,327(55.41)$ & $188,392(86.29)$ & $29,935(13.71)$ & & \\
\hline Others & $10,650(2.70)$ & $10,248(96.23)$ & $402(3.77)$ & & \\
\hline \multicolumn{6}{|l|}{ Type of drug } \\
\hline Chemical compound & $302,078(76.66)$ & $273,904(90.67)$ & $28,174(9.33)$ & \multirow{3}{*}{$<0.001$} & \multirow{3}{*}{0.410} \\
\hline Chinese patent medicine & $72,218(18.33)$ & $66,777(92.47)$ & $5441(7.53)$ & & \\
\hline Imported and biologics & $12,163(3.09)$ & $10,415(85.63)$ & $1748(14.37)$ & & \\
\hline \multicolumn{6}{|l|}{ Past history } \\
\hline No & $257,061(65.24)$ & $233,255(90.74)$ & $23,806(9.26)$ & \multirow{3}{*}{$<0.001$} & \multirow{3}{*}{0.570} \\
\hline Yes & $5922(1.50)$ & $4648(78.49)$ & $1274(21.51)$ & & \\
\hline Unknown & $131,054(33.26)$ & $120,392(91.86)$ & $10,662(8.14)$ & & \\
\hline \multicolumn{6}{|l|}{ ADRs occurrence } \\
\hline First & $387,642(98.38)$ & $352,672(90.98)$ & $34,970(9.02)$ & \multirow{2}{*}{$<0.001$} & \multirow{2}{*}{0.013} \\
\hline Again & $6395(1.62)$ & $5623(87.93)$ & $772(12.07)$ & & \\
\hline \multicolumn{6}{|l|}{ New ADRs } \\
\hline Yes & $101,727(25.82)$ & $91,208(89.66)$ & $10,519(10.34)$ & \multirow{2}{*}{$<0.001$} & \multirow{2}{*}{0.026} \\
\hline No & $292,310(74.18)$ & $267,087(91.37)$ & $25,223(8.63)$ & & \\
\hline
\end{tabular}

Table 1. The severity of adverse drug reactions was different in patients with different characteristic.

\begin{tabular}{|c|c|c|c|c|c|}
\hline Variables & Total N (\%) & Nonserious N (\%) & Serious $\mathrm{N}(\%)$ & $P$ value & Effect size $(\varphi)$ \\
\hline Total & $394,037(100)$ & $358,295(90.58)$ & $35,742(9.42)$ & & \\
\hline \multicolumn{6}{|l|}{ Results } \\
\hline Better & 378,497 (96.06) & $351,276(98.00)$ & $27,221(76.20)$ & \multirow{6}{*}{$<0.001$} & \multirow{6}{*}{0.332} \\
\hline Not better & $13,066(3.31)$ & $5486(1.50)$ & $7580(21.20)$ & & \\
\hline Worse & $1720(0.44)$ & $1302(0.40)$ & $418(1.20)$ & & \\
\hline Not better and worse & $601(0.15)$ & $184(0.10)$ & $417(1.20)$ & & \\
\hline Sequela & $114(0.03)$ & $47(0.01)$ & $67(0.20)$ & & \\
\hline Death & $39(0.01)$ & $0(0.00)$ & $39(0.10)$ & & \\
\hline
\end{tabular}

Table 2. The severity of ADRs was different in patients with different characteristics. 


\begin{tabular}{|c|c|c|}
\hline Primary health institutions & \begin{tabular}{|l|} 
Yes \\
OR (95\% CI)
\end{tabular} & \begin{tabular}{|l} 
No \\
OR $(95 \% \mathrm{CI})$
\end{tabular} \\
\hline \multicolumn{3}{|l|}{ Gender (refer to male) } \\
\hline Female & $0.956(0.91-1.003)$ & $1.034^{*}(1.004-1.064)$ \\
\hline \multicolumn{3}{|l|}{ Age (refer to 18-35) } \\
\hline $0-6$ & $0.848^{*}(0.742-0.969)$ & $0.950(0.884-1.022)$ \\
\hline $6-18$ & $0.912(0.805-1.034)$ & $1.208^{* *}(1.109-1.317)$ \\
\hline $35-60$ & $1.082^{*}(1.005-1.166)$ & $1.324^{* *}(1.262-1.389)$ \\
\hline $60-80$ & $1.145^{\star *}(1.062-1.234)$ & $1.496^{* *}(1.427-1.570)$ \\
\hline$>80$ & $1.225^{\star *}(1.078-1.392)$ & $1.341^{* *}(1.253-1.435)$ \\
\hline \multicolumn{3}{|l|}{ Number of diseases (refer to 1 ) } \\
\hline$\geq 2$ & $1.394^{* *}(1.274-1.525)$ & $1.207^{* *}(1.166-1.250)$ \\
\hline \multicolumn{3}{|l|}{ Polypharmacy (refer to no) } \\
\hline yes & $2.708^{* *}(1.613-4.548)$ & $3.332^{* *}(2.963-3.747)$ \\
\hline \multicolumn{3}{|c|}{ Type of drug (refer to chemical compound) } \\
\hline Chinese patent medicine & $1.079^{* *}(1.022-1.139)$ & $0.936^{* *}(0.899-0.975)$ \\
\hline Imported and biological product & $1.173(0.990-1.390)$ & $1.392^{* *}(1.311-1.478)$ \\
\hline \multicolumn{3}{|l|}{ Past history (refer to no) } \\
\hline Yes & $1.625^{\star *}(1.222-2.161)$ & $1.884^{* *}(1.754-2.025)$ \\
\hline Unknown & $0.789^{* \star}(0.753-0.827)$ & $1.043^{* *}(1.011-1.075)$ \\
\hline \multicolumn{3}{|l|}{ Past behavior (refer to no) } \\
\hline Smoking and drinking & $1.333^{\star *}(1.242-1.430)$ & $1.198^{* *}(1.136-1.263)$ \\
\hline Allergy & $0.875(0.643-1.190)$ & $1.080(0.982-1.189)$ \\
\hline History of illness and surgery & $0.964(0.752-1.234)$ & $1.304^{* *}(1.197-1.420)$ \\
\hline \multicolumn{3}{|l|}{ Medication (refer to oral) } \\
\hline Injection & $7.353^{* *}(6.947-7.783)$ & $3.335^{\star *}(3.205-3.469)$ \\
\hline Others & $1.016(0.742-1.392)$ & $1.054(0.936-1.188)$ \\
\hline \multicolumn{3}{|c|}{ Time from medication to ADR (refer to $<3$ ) } \\
\hline$\geq 3$ & $1.368^{\star *}(1.221-1.533)$ & $2.312^{* *}(2.241-2.385)$ \\
\hline \multicolumn{3}{|l|}{ Season (refer to spring) } \\
\hline Summer & $1.185^{* *}(1.109-1.265)$ & $1.033(0.993-1.074)$ \\
\hline Autumn & $1.387^{\star *}(1.304-1.476)$ & $1.193^{* *}(1.150-1.238)$ \\
\hline Winter & $1.560^{\star *}(1.439-1.691)$ & $1.135^{* *}(1.085-1.186)$ \\
\hline \multicolumn{3}{|l|}{ ADRs occurrence (refer to first) } \\
\hline Again & $0.768(0.569-1.037)$ & $0.870^{* *}(0.792-0.956)$ \\
\hline \multicolumn{3}{|l|}{ New adverse reactions (refer to no) } \\
\hline Yes & $1.597^{* *}(1.524-1.673)$ & $1.385^{\star *}(1.342-1.429)$ \\
\hline
\end{tabular}

Table 3. SADRs in primary and non-primary medical institutions.

The results of the present research suggest that general factors, such as age, disease, type of drug, medication way, new and recurring ADRs and multiple medications, increase the probability of SADRs. Once SADR occurs, it is likely to lead to aggravation of the patient's original illness and sequelae, which can lead to death in severe cases ${ }^{16-19}$. All 39 deaths are caused by SADRs. The causes of death are hemorrhages and organ failure ${ }^{20}$. The present study has also found that high-level medical institutions have a high proportion of SADRs although people generally think that these institutions are standardized and safe ${ }^{21}$, and this may be due to the fact that high-level medical institutions use multiple drugs and newly developed drugs more commonly. Season is also a factor that should be paid attention. The proportion of SADRs increased significantly in autumn and winter. It may be that the autumn and winter seasons are more susceptible to influenza, and the patient's physique is weaker than other seasons during this period ${ }^{22,23}$.

Overall, this research on primary and nonprimary medical institutions in Table 3 shows that the risk of SADRs in people with multiple medications and having experienced ADRs is quite high. This result further proves the danger of multiple medications and reminds medical staff that they should take special care of patients who have $\mathrm{ADRs}^{24}$. However, different factors cause different results in different levels of medical institutions. For example, patients who use proprietary Chinese medicines in primary medical institutions have a higher risk of SADRs than those who use compound drugs, but the opposite is true in nonprimary medical institutions. This finding may be because the indications of traditional Chinese medicine preparations are wide, and the ADRs of some raw materials are not yet clear. The primary medical institutions cannot fully grasp this information ${ }^{25}$. Injection, as one of the risk factors for SADRs, is evident at the primary level ${ }^{26,27}$. This finding reminds primary medical institutions of the need to strengthen the management of proprietary Chinese medicines and injections ${ }^{28}$. Primary medical 


\begin{tabular}{|c|c|c|}
\hline Primary health institutions & $\begin{array}{l}\text { Yes } \\
\text { OR }(95 \% \mathrm{CI})\end{array}$ & \begin{tabular}{|l|} 
No \\
OR $(95 \%$ CI $)$
\end{tabular} \\
\hline \multicolumn{3}{|l|}{ Gender (refer to male) } \\
\hline Female & $0.984(0.880-1.021)$ & $1.078^{\star *}(1.034-1.124)$ \\
\hline \multicolumn{3}{|l|}{ Age (refer to 18-35) } \\
\hline $0-6$ & $0.804^{\star}(0.647-0.999)$ & $0.669^{* *}(0.598-0.749)$ \\
\hline $6-18$ & $0.854(0.701-1.041)$ & $0.887(0.780-1.009)$ \\
\hline $35-60$ & $0.972(0.870-1.087)$ & $1.015(0.952-0.082)$ \\
\hline $60-80$ & $1.075(0.960-1.204)$ & $1.122^{* *}(1.052-1.196)$ \\
\hline$>80$ & $1.373^{\star}(1.140-1.654)$ & $1.029(0.935-1.133)$ \\
\hline \multicolumn{3}{|l|}{ Number of diseases (refer to 1) } \\
\hline$\geq 2$ & $1.651^{\star *}(1.449-1.881)$ & $1.197^{\star *}(1.139-1.259)$ \\
\hline \multicolumn{3}{|l|}{ Polypharmacy (refer to no) } \\
\hline Yes & $5.145^{\star \star}(2.862-9.248)$ & $4.004^{\star \star}(3.502-4.579)$ \\
\hline \multicolumn{3}{|c|}{ Type of drug (refer to chemical compound) } \\
\hline Chinese patent medicine & $0.805^{\star *}(0.736-0.880)$ & $0.639^{* *}(0.596-0.685)$ \\
\hline Imported and biological product & $0.654^{\star}(0.453-0.943)$ & $1.200^{* *}(1.107-1.302)$ \\
\hline \multicolumn{3}{|l|}{ Past history (refer to no) } \\
\hline Yes & $2.671^{\star *}(1.870-3.813)$ & $2.237^{\star *}(2.036-2.459)$ \\
\hline Unknown & $1.068(0.995-1.146)$ & $1.246^{* *}(1.194-1.301)$ \\
\hline \multicolumn{3}{|l|}{ Past behavior (refer to no) } \\
\hline Smoking and drinking & $1.215^{\star \star}(1.090-1.354)$ & $1.511^{\star *}(1.408-1.623)$ \\
\hline Allergy & $1.620^{* *}(1.130-2.322)$ & $1.092(0.951-1.254)$ \\
\hline History of illness and surgery & $0.916(0.614-1.368)$ & $1.574^{\star *}(1.408-1.760)$ \\
\hline \multicolumn{3}{|l|}{ Medication (refer to oral) } \\
\hline Injection & $1.938^{\star *}(1.804-2.082)$ & $1.188^{* *}(1.136-1.243)$ \\
\hline Others & $2.096^{\star *}(1.627-2.701)$ & $0.917(0.799-1.054)$ \\
\hline \multicolumn{3}{|c|}{ Time from medication to ADR (refer to $<3$ ) } \\
\hline$\geq 3$ & $2.345^{\star \star}(2.073-2.653)$ & $3.686^{\star *}(3.539-3.839)$ \\
\hline \multicolumn{3}{|l|}{ Season (refer to spring) } \\
\hline Summer & $1.008(0.912-1.114)$ & $1.033(0.976-1.093)$ \\
\hline Autumn & $1.145^{\star *}(1.043-1.257)$ & $1.099^{*}(1.041-1.161)$ \\
\hline Winter & $1.350^{\star *}(1.196-1.523)$ & $1.186^{\star *}(1.114-1.264)$ \\
\hline \multicolumn{3}{|l|}{ ADRs occurrence (refer to first) } \\
\hline Again & $0.505^{\star}(0.291-0.879)$ & $1.011(0.895-1.142)$ \\
\hline \multicolumn{3}{|l|}{ New adverse reactions (refer to no) } \\
\hline Yes & $1.325^{\star *}(1.230-1.426)$ & $0.872^{\star *}(0.828-0.918)$ \\
\hline
\end{tabular}

Table 4. ADRs in primary and non-primary medical institutions lead to results. OR odds ratio, CI confidence interval. ${ }^{*} p<0.05,{ }^{* *} p<0.01$.

institutions pay more attention to patients who are not sure whether they have SADRs and history of drug allergies than other hospitals. Their risk of SADRs is lower than that in normal people, which may be the result of the combination of drug use methods in primary medical institutions and attention to special populations ${ }^{29}$.

The report on the prognosis of ADRs is similar to those of previous studies. All medical institutions' patients with multiple medications, history of ADRs, injection, smoking and drinking and patients with a time interval more than three days have worse prognosis ${ }^{24,30,31}$. This report also found the probability of poor prognosis in nonprimary medical institutions increases in winter. This phenomenon may be due to the shortage of medical beds and insurance funds at the end of the year ${ }^{21}$. In addition, this study has found that although the risk of SADRs caused by minor is high, the prognosis of ADRs in minors is better than adults. This finding shows that medical institutions should pay attention to the risks of the elderly patient. In particular, non-primary medical institutions need to pay more attention to the elderly ( $>80$ years old) patients because these institutions undertaked more tasks ${ }^{32}$.

The prognosis of patients in primary medical institutions who use other methods of drug delivery is worse because of the lack of professionals or equipment. Patients with drug allergies have worse prognosis ${ }^{33}$. This finding may be the lack of the corresponding training in primary medical institutions. Compared with non-primary institutions, the prognosis of patients with recurrent ADRs is better, indicating that the primary medical institutions are more cautious towards patients with a history of ADRs, however, the prognosis of patients with new ADRs is worse in primary medical institutions and better in non-primary institutions, and it may be due to the fact that primary medical institutions lack effective response measures to new ADRs. 


\section{Limitations}

This study has several limitations. First, due to the limitation of data source, the study uses the database of Henan Province, which does not necessarily represent the true situation of the whole country. Second, the database is large and difficult to clean. This study has not analyzed the specific drugs and symptoms that cause ADRs. Third, some recorded ADRs information is not complete, and there are a few missing values in some indicators, which may cause a certain degree of bias. Fourth, due to the insufficient content of the original database, this study has not specifically analyzed the relationship between ADRs and drugs used. Finally, And media attention and recent publication of an ADR in the literature might affect the reporting behaviors ${ }^{34}$.

\section{Conclusion}

This study analyzes the influencing factors and countermeasures of ADRs. The absolute number of SADRs is increasing, and a high proportion occurs in nonprimary medical institutions. Patients with multiple medications, history of ADRs, and the interval between medication and ADRs exceeding three days have high risk of SADRs and poor prognosis. Other factors lead to different results in different levels of medical institutions. We suggest strengthening the supervision of proprietary Chinese medicines and injections; Introduce a plan to deal with new ADRs in primary medical institutions and paying attention to the safety and health status of patients with history and used imported drugs and biologic with caution in nonprimary medical institutions.

Received: 2 July 2021; Accepted: 30 September 2021

Published online: 14 October 2021

\section{References}

1. Edwards, I. R. \& Aronson, J. K. Adverse drug reactions: Definitions, diagnosis, and management. Lancet 356(9237), 1255-1259 (2000).

2. Pirmohamed, M. et al. Adverse drug reactions. BMJ 316(7140), 1295-1298 (1998).

3. Cameron, H. A. \& Ramsay, L. E. The lupus syndrome induced by hydralazine: A common complication with low dose treatment. Br. Med. J. (Clin. Res. Ed.) 289(6442), 410-412 (1984).

4. Mallal, S. et al. HLA-B ${ }^{\star} 5701$ screening for hypersensitivity to abacavir. N. Engl. J. Med. 358(6), 568-579 (2008)

5. Lazarou, J., Pomeranz, B. H. \& Corey, P. N. Incidence of adverse drug reactions in hospitalized patients: A meta-analysis of prospective studies. JAMA 279(15), 1200-1205 (1998).

6. Chyka, P. A. How many deaths occur annually from adverse drug reactions in the United States?. Am. J. Med. 109(2), 122-130 (2000).

7. Bates, D. W. et al. Incidence of adverse drug events and potential adverse drug events. Implications for prevention. ADE prevention study group. JAMA 274(1), 29-34 (1995).

8. Bates, D. W. et al. The costs of adverse drug events in hospitalized patients. Adverse drug events prevention study group. JAMA 277(4), 307-311 (1997).

9. National Annual Report on Adverse Drug Reaction Monitoring in 2021. [EB/OL]. (2021-03-26)[06]. http://www.cdr-adr.org.cn/ tzgg_home/202103/t20210326_48414.html.

10. Jefferys, D. B. et al. New active substances authorized in the United Kingdom between 1972 and 1994. Br. J. Clin. Pharmacol. 45(2), 151-156 (1998).

11. Zhang, X. et al. Adverse drug reaction reporting in institutions across six Chinese provinces: A cross-sectional study. Expert Opin. Drug Saf. 18(1), 59-68 (2019).

12. Guo, X. J. et al. Reporting patterns of adverse drug reactions over recent years in China: Analysis from publications. Expert Opin. Drug Saf. 14(2), 191-198 (2015).

13. Adverse Drug Reaction Reporting and Monitoring Management Measures (Ministry of Health Order No.81) [EB/OL]. [2021/5/25]. http://www.gov.cn/flfg/2011-05/24/content_1870110.htm.

14. Zhang, L. et al. Pharmacovigilance in China: Current situation, successes and challenges. Drug Saf. 37(10), 765-770 (2014).

15. Wang, J. G. \& Wang, N. The present situation and management measures of adverse drug reactions in China. In Advances in Social Science Education and Humanities Research (eds Hee, T. \& Liu, J.) 311-314 (Atlantis Press, 2016).

16. Jiang, C. et al. Identification of high-risk patients for ADR induced by traditional Chinese medicine injection: A nested case-control study. Sci. Rep. 9(1), 16721 (2019).

17. Sandoval, T. et al. Incident adverse drug reactions and their effect on the length of hospital stay in older inpatients. Int. J. Clin. Pharm. 43, 839-846 (2020).

18. Mendes, D. et al. Spontaneous reports of hypersensitivity adverse drug reactions in Portugal: A retrospective analysis. Expert Opin. Drug Saf. 19(6), 763-769 (2020).

19. Modi, A. et al. Analysis of cutaneous adverse drug reactions reported at the regional ADR monitoring center. Indian J. Dermatol. 64(3), 250 (2019).

20. Wester, K. et al. Incidence of fatal adverse drug reactions: A population based study. Br. J. Clin. Pharmacol. 65(4), 573-579 (2008).

21. Guner, M. D. \& Ekmekci, P. E. Healthcare professionals' pharmacovigilance knowledge and adverse drug reaction reporting behavior and factors determining the reporting rates. J. Drug Assess 8(1), 13-20 (2019).

22. Chabanon, A. L. et al. Enhanced passive safety surveillance of the quadrivalent inactivated split-virion influenza vaccine (IIV4) in Finland during the 2019/20 influenza season. BMC Public Health 21(1), 358 (2021).

23. Deb, T. et al. Impact of climatic variations on drug-induced skin reactions in two different regions of India. Curr. Drug Saf. 16(1), 90-96 (2021).

24. Liu, Y. et al. Influencing factors and their relationships of risk perception and decision-making behaviour of polypharmacy in patients with chronic diseases: A qualitative descriptive study. BMJ Open 11(4), e43557 (2021).

25. Zhang, W. et al. Patient expectations and awareness of information regarding adverse reactions in drug labelling in China. Int. J. Clin. Pharm. 43(1), 174-180 (2021).

26. Li, H. et al. Safety profile of traditional Chinese herbal injection: An analysis of a spontaneous reporting system in China. Pharmacoepidemiol. Drug Saf. 28(7), 1002-1013 (2019).

27. Wang, J. G. \& Wang, N. Supervisory control of adverse reaction of traditional chinese medicine injection. In Advances in Social Science Education and Humanities Research (eds Xiao, X. et al.) 167-169 (Atlantis Press, 2017).

28. Hu, Q. et al. Influencing factors for adverse drug reactions of Chinese herbal formula aidi injection. J. Med. Imaging Health Inform. 7(6), 1226-1232 (2017).

29. Bigi, C. \& Bocci, G. The key role of clinical and community health nurses in pharmacovigilance. Eur. J. Clin. Pharmacol. 73(11), 1379-1387 (2017) 
30. Ogar, C. K. et al. A retrospective review of serious adverse drug reaction reports in the Nigerian VigiFlow database from September 2004 to December 2016. Pharmaceut. Med. 33(2), 145-157 (2019).

31. Oreagba, I. A. et al. Adverse reactions to fluoroquinolones in the Nigerian population: An audit of reports submitted to the National Pharmacovigilance Centre from 2004 to 2016. Pharmacol. Res. Perspect. 5(2), e297 (2017).

32. Varallo, F. R., Planeta, C. S. \& Mastroianni, P. C. Effectiveness of pharmacovigilance: Multifaceted educational intervention related to the knowledge, skills and attitudes of multidisciplinary hospital staff. Clinics (Sao Paulo) 72(1), 51-57 (2017).

33. Faria, E. et al. Drug-induced anaphylaxis survey in Portuguese Allergy Departments. J. Investig. Allergol. Clin. Immunol. 24(1), 40-48 (2014).

34. Patek, T. M. et al. Comparing acute kidney injury reports among antibiotics: A pharmacovigilance study of the FDA adverse event reporting system (FAERS). Drug Saf. 43(1), 17-22 (2020).

\section{Acknowledgements}

The authors would like to thank the Henan Adverse Drug Reaction Monitoring Center for providing the data. The data in this study is publicly available and accessible. The information in this paper does not represent the opinion of Henan Adverse Drug Reaction Monitoring Center or national centres. The National Natural Science Foundation of China (No. 72074088) and the Young Scientists Fund (No. 71804052) supported this research. We would like to thank the National Natural Science Foundation of China and the Young Scientists Fund for the funding for this research.

\section{Author contributions}

Z.F., G.W. and D.F. obtained and collected the data; D.F. conceived and conducted the study; Z.Y., Z.J. and C.C. cleaned and pre-processed the data; Z.Y., Z.J. analysed the results; Z.Y. wrote the manuscript. All authors reviewed the manuscripthave and they have no conflict of interest directly relevant to the content of this article.

\section{Competing interests}

The authors declare no competing interests.

\section{Additional information}

Correspondence and requests for materials should be addressed to D.F.

Reprints and permissions information is available at www.nature.com/reprints.

Publisher's note Springer Nature remains neutral with regard to jurisdictional claims in published maps and institutional affiliations.

(c) (i) Open Access This article is licensed under a Creative Commons Attribution 4.0 International License, which permits use, sharing, adaptation, distribution and reproduction in any medium or format, as long as you give appropriate credit to the original author(s) and the source, provide a link to the Creative Commons licence, and indicate if changes were made. The images or other third party material in this article are included in the article's Creative Commons licence, unless indicated otherwise in a credit line to the material. If material is not included in the article's Creative Commons licence and your intended use is not permitted by statutory regulation or exceeds the permitted use, you will need to obtain permission directly from the copyright holder. To view a copy of this licence, visit http://creativecommons.org/licenses/by/4.0/.

(c) The Author(s) 2021, corrected publication 2022 